\title{
A Pilot-study of the use of Nutrition-related Apps and Software in Africa during the COVID-19 Pandemic
}

\author{
Alex Tchuenchieu ${ }^{1,2 *}$, Hema Kesa ${ }^{1}$, Gifty Koufie ${ }^{1}$, Eridiong O. Onyenweaku ${ }^{1}$ \\ ${ }^{1}$ Food Evolution Research Laboratory, School of Tourism and Hospitality, College of Business and Economics, University of \\ Johannesburg, South Africa. \\ ${ }^{2}$ Centre for Food and Nutrition Research, Institute of Medical Research and Medicinal Plants Studies, Yaoundé, Cameroon.
}

Received 11 February 2021; Revised 12 April 2021; Accepted 18 April 2021; Published 27 April 2021

\begin{abstract}
The ongoing COVID-19 pandemic and the associated lockdown measures have risen the malnutrition problem in the world, especially in Africa. The use of nutrition apps/software at individual level therefore appears as suitable solution given the context. This study aimed at assessing the actual usage level of nutrition apps/software and the determining factors. A crosssectional study consisting of an online-survey conducted from April to May 2020 with as target Africans aged of 18 and above was carried out. A total of 460 respondents from different African countries was registered. Globally they appeared to have started using computer and smartphones since at least 5 years and this mostly at a daily frequency together with internet. A total of $52.2 \%$ of the respondents recognized not to apply or not to know if they apply the principles of a balanced diet in their day-to-day life, but just $18 \%$ reported to be using a nutrition apps/software; COVID-19 pandemic having pushed $7 \%$ to refer more to these tools and $0.7 \%$ to start using one. South Africa nationals, people living in a household of 3-5 people and those having a monthly income above 500 USD tended to use them more. Almost half of the users report that these tools do not take into consideration foods available in their context. On the other hand, almost half of the non-users ( $41.5 \%$ of respondents) said they would prefer to be advised by a dietician. However up to $50.9 \%$ clearly stated they are interested in learning more about these tools, which is of quite of big interest in preventing Noncommunicable diseases resurgence in relation to COVID-19 pandemic.
\end{abstract}

Keywords: Africa; COVID-19; Eating Habits; Non-communicable Diseases; Nutri-apps.

\section{Introduction}

The COVID-19 pandemic which started since December 2019 from China has spread at an astonishing rate worldwide. Many countries affected by this disease have adopted lockdown strategies in order to control the disease. These restrictive measures that are partial or total from one country to another suggests populations remaining indoors and working from home. It is estimated that half of the world population, have been asked or ordered to stay at home for a certain period of time by their governments. Physical inactivity, smoking and alcohol consumption are often reported as population habits during that period [1-3]. Furthermore, malnutrition either in terms of quantity or quality cannot be excluded [4]. In fact, overeating and the consumption of unhealthy foods when staying at home for a long-period is common, leading to overweight and obesity $[5,6]$. On the other hand, many persons might change their eating habits taking into consideration factors like foods availability or prices (food insecurity). Situations of undernutrition or unbalanced diet arising from the ongoing coronavirus pandemic are certain. Unfortunately, smoking, malnutrition,

* Corresponding author: kamgaina@uj.ac.za

doi http://dx.doi.org/10.28991/SciMedJ-2021-03-SI-3

$>$ This is an open access article under the CC-BY license (https://creativecommons.org/licenses/by/4.0/).

(C) Authors retain all copyrights. 
physical inactivity and alcohol misuse are recognised as behavioural risk factors causing non-communicable diseases (NCDs). These diseases, also known as chronic diseases, were reported to account for $71 \%$ of the 57 million deaths that occurred globally in 2016 [7, 8] in comparison to the 6\% world mortality rate of the COVID-19 [9]. Cardiovascular diseases, cancers, chronic respiratory diseases and diabetes represent those with the highest prevalence, unhealthy diet being the main cause among the 4 previously cited [10]. As reported by the World Health Organization, $85 \%$ of deaths associated to these NCDs occur in low- and middle-income countries and in vulnerable communities where access to preventative healthcare is lacking. Besides, a greater COVID-19 mortality is known for persons already suffering from these NCDs $[11,12]$. This therefore increase the public health concern as COVID-19 pandemic has been declared by WHO in August 2020 to be probably of long duration as no vaccine has been completely tested. Many nutrition apps and software have been developed during the last decades in order to promote healthy nutrition within populations [13, 14]. They have gained popularity in the past decade as effective self-help alternatives that are complimentary to a dietician's intervention. They act as effective catalyst for promoting healthy lifestyles, shaping behaviour and improve consumer knowledge on the nutritional value of foods [13]. In clinical settings, researchers and doctors have found such applications useful in monitoring patient's recovery performance, dietary intake, eating pattern and relative effectiveness of dietary prescription [15]. They have become increasingly prevalent [16] but their use is not yet systematic. Africa is one of the continents mostly concerned by the double burden of malnutrition (undernutrition and overweight/obesity) [17] and is also facing the COVID-19. As the continent is gradually turning more towards the 4th Industrial Revolution, the use of Nutri apps or software may therefore be of interest in order to avoid the above described lethal snowball effect between COVID-19 and NCDs. These tools are perhaps the most potent medium for delivering healthcare assistance with less cost burden and mobility in these present times. In this perspective, this study aims at assessing the actual usage level of Nutri apps or software in African countries and the determining factors.

\section{Research Methodology}

\subsection{Study Design and Participants}

The cross-sectional study was conducted between April and May 2020. The data was collected using an online survey form that only Africans aged of 18 and above were invited to complete. This approach appeared as the best considering the COVID-19 lockdown measures. The African Nutrition Leadership Programme (ANLP) Alumni Network assisted with the data collection and was helpful in ensuring data could be collected across different African countries.

\subsection{Data Collection}

Data was collected using a well-structured questionnaire which consisted of four main sections namely Sociodemographic; Health; Computer and Smartphone use experience; Nutrition Apps/Software and personal experience. The questionnaire was simultaneously prepared in French and English languages as these are the main official languages in African countries. The questionnaire was piloted on 25 people and suggestions inserted in the final questionnaire.

\subsection{Ethical Statement}

The research proposal was reviewed and approved by the Ethics Committee of Research of the University of Johannesburg. All participating respondents voluntarily and anonymously filled the online survey form.

\subsection{Data Analysis}

The collected data was exported and coded in an excel folder. The statistical software SPSS (Statistical Package for Social Sciences), version 25.0 was then used to perform descriptive statistics. This software was also use for the ANOVA analysis of the Computer, Smartphone and Internet (CSI) use experience score of respondents per studied sociodemographic. parameter. Indeed, for each of the 5 questions asked to assess this experience, a score from 1 (low experience) to 4 (high experience) was given, and the total score out of 20 calculated.

\section{Results and Discussion}

\subsection{Sociodemographic Characteristics of the Surveyed Population}

A total of 460 people participated to this study with 30.4\% from Central Africa [Cameroon (133), Chad (2), Gabon (4), Republic Democratic of Congo (1)]; 26.7\% from West Africa [ Nigeria (117), Mali (2), Ivory coast (1), Senegal (1), Liberia (1), Niger (1)]; 25.7\% from Southern Africa [South Africa (116), Malawi (1), Mozambique (1)]; 9.3\% from North Africa [Algeria (4), Egypt (3), Morocco (35), Tunisia (1)]; and 7.8\% from Eastern Africa [Uganda (17), Ethiopia (13), South Sudan (2), Kenya (1), Sudan (1), Rwanda (1), Tanzania (1)]. The population was largely comprised of females $(61.1 \%)$ and grouped into 4 different races (77.8\% Black, 7.6\% Coloured, $4.8 \%$ Indian and 9.8\% White). Among them, $41.1 \%$ were aged between 30 and 49 years old, while $47.6 \%$ and $11.3 \%$ were younger and older, respectively. 
About $91.3 \%$ had tertiary education meanwhile $8 \%$ had secondary education and $0.6 \%$ less. Only $29.1 \%$ lived in a household of 1-2 persons, the others living in either a 3-5 persons households $(52.6 \%)$ or above (18.3\%). Some reported to have a monthly income lower than 100USD (21.1\%), and others fell in the range of 100-300USD (31.5\%), 301500USD (21.7\%), and above 500USD (25.7\%).

\subsection{Computer, Smartphone and Internet (CSI) use Experience}

Among the respondents, $57.8 \%$ have been using computer for more than 10 years, $22.8 \%$ between $6-10$ years and $13.5 \%$ between $1-5$ years. Just $5.9 \%$ reported to have used one for less than 1 year. Concerning Smartphone, $42.8 \%$ declared a usage experience ranging from 6-10 years meanwhile 35\% were above 10 years, 19.6\% between 1-5 years and $2.6 \%$ below one year. In contrast to smartphone where the use is almost daily (96.5\%), computer used was either daily $(65.2 \%)$ or weekly $(13.2 \%)$. This is also the case for internet connection that tended to be daily (92.4\%) or at least weekly (4.6\%). This may suggest an increase in the CSI use in Africa. In fact, in 2017, smartphones ownership as well as internet use had already been described as more common around the globe, Africa being behind with countries like South Africa, Ghana, Senegal, Nigeria, Tunisia, Kenya and Tanzania leading the chart [18]. Today, smartphones are no longer a luxury [19] and are used by millions of people not only for fun, but for regular communication with friends, family and colleagues, email access, internet access, efficiency, and connectivity. The continuous improvement of smartphones over the years is one of the main drivers that contributed to the rapidly growing numbers of mobile applications, as well as different mobile categories [18].

The calculation of the CSI score (Table 1) clearly shows that overall population has a high usage experience, the lowest minimal mean value being 16 over 20 . This CSI score appeared to be significantly determined by all the above described socio-demographics parameters of the surveyed population. In fact, people from Eastern and Southern Africa, males, coloured people, people aged between 30-49 years old, those with tertiary education level, those living in a house of maximum 2 persons, and those having a monthly income above 500USD presented the highest score.

\subsection{Nutrition Apps and Software usage Level}

The rapid developments in mobile technology have encouraged the use of smartphones in health promotion research and practice. Although many applications (apps) related to diet and nutrition are available from major smartphone platforms, relatively few empirical studies have been conducted on their effectiveness in promoting healthy eating behaviour [20]. Electronic health (eHealth) and mobile health (mHealth) technologies including mobile devices, and smartphone applications (apps), provide opportunities for population wide promotion of physical activity and healthy eating [21]. As shown in Table 2, 93.9\% of studied population declared they know what a balanced diet is, and to have heard about from nutrition courses they took (50.4\%), their doctor/nutritionist or dietician (32.4\%) and personal reading (32.2\%), Social media (28.3\%) and Radio/TV (27\%). However, $41.5 \%$ admitted not applying its principles in their dayto-day life. A high percentage of this population (82\%) was not using any nutrition app/software. The most used one appeared to be Samsung Health app (7.4\%), MyFitnessPal (3.7\%), Fitbit (2.8\%), CarbsControl (1.1\%), Fitocracy (1.1\%) and Fooducate $(1.1 \%)$. This preference to Samsung Health app may come from the fact that Samsung Smartphones already integrate that app compared to the other apps that the owner have to download and installed. For those using one, reasons like calories intake monitoring; Keep fit/Healthy diet or lifestyle; weight loss or program already installed on my phone were enounced. On the other hand, those not using gave reasons like no interest/reason to use/need; Nonawareness; Financial reason (Access); Unavailability of some food suggested or unaffordability; Medical reason; Lazyness; Personnal Instructor and lack of time. From the $18 \%$ of users, $10.7 \%$ have been using nutrition apps/software for just 1-5 years. A positive appreciation of their effectiveness in solving the problem they are used for was given by $9.5 \%$ of the respondents while $7.6 \%$ gave an average opinion and $0.9 \%$ a negative one. The COVID-19 pandemic has pushed just $0.7 \%$ to start using one, and $7 \%$ to refer more to these tools. This emphasizes the risk of a rise of the double burden malnutrition.

A comparison of the number of users and non-users per socio-demographic parameter can be made with Table 3 . Region, race, household size and monthly income appeared as the only socio-demographic parameters significantly determining that number. Southern Africa was by far the region with the highest users, followed by West Africa. People living in a household of 3-5 people and those having a monthly income above 500 USD tended to use those tools more. Besides, the number of users tended to decrease with respondents age (8.9\% for the $18-29$ years old; $7.6 \%$ for the $30-49$ years old; and $1.5 \%$ for the 50 years old and older). Similar observation was made by Kunst [22] when studying the usage of these tools among 962 US adults and who reported 64\% of users among 18-29 years old respondents, $60 \%$ among 30-45 years old respondents, 27\% among 46-60 years old respondents, and just 15\% for those older. In fact, Millennials who are a generational cohort born between 1980 and 2000 "grew up with technology" are perceived to have the highest affinity for technology [23]. To Millennials, technology is as essential to life as is the food they eat and the clothes they wear [24]. 
Table 1. Change of CSI score with the sociodemographic variables $(N=460)$

\begin{tabular}{|c|c|c|c|c|c|c|c|c|c|c|}
\hline \multirow{2}{*}{\multicolumn{2}{|c|}{ Variable }} & \multicolumn{4}{|c|}{ Score } & \multicolumn{5}{|c|}{ ANOVA between groups } \\
\hline & & Mean & $\begin{array}{c}\text { Std. } \\
\text { Deviation }\end{array}$ & Minimum & Maximum & $\begin{array}{l}\text { Sum of } \\
\text { Squares }\end{array}$ & df & $\begin{array}{c}\text { Mean } \\
\text { Square }\end{array}$ & $\mathbf{F}$ & p-value \\
\hline \multirow{5}{*}{ Region } & Central Africa & 16.03 & 3.726 & 3 & 20 & \multirow{5}{*}{470.388} & \multirow{5}{*}{4} & \multirow{5}{*}{117.597} & \multirow{5}{*}{14.687} & \multirow{5}{*}{0.000} \\
\hline & Eastern Africa & 18.28 & 1.892 & 11 & 20 & & & & & \\
\hline & North Africa & 17.98 & 2.395 & 9 & 20 & & & & & \\
\hline & Southern Africa & 18.58 & 1.814 & 11 & 20 & & & & & \\
\hline & West Africa & 17.27 & 2.808 & 8 & 20 & & & & & \\
\hline \multirow{2}{*}{ Gender } & Female & 16.93 & 3.319 & 3 & 20 & \multirow{2}{*}{139.393} & \multirow{2}{*}{1} & \multirow{2}{*}{139.393} & \multirow{2}{*}{16.065} & \multirow{2}{*}{0.000} \\
\hline & Male & 18.06 & 2.236 & 3 & 20 & & & & & \\
\hline \multirow{4}{*}{ Race } & Black & 17.11 & 3.169 & 3 & 20 & \multirow{4}{*}{119.676} & \multirow{4}{*}{3} & \multirow{4}{*}{39.892} & \multirow{4}{*}{4.555} & \multirow{4}{*}{0.004} \\
\hline & Coloured & 18.69 & 1.132 & 15 & 20 & & & & & \\
\hline & Indian & 18.09 & 2.114 & 13 & 20 & & & & & \\
\hline & White & 18.09 & 2.485 & 9 & 20 & & & & & \\
\hline \multirow{3}{*}{ Age } & $18-29$ & 16.94 & 2.702 & 8 & 20 & \multirow{3}{*}{232.059} & \multirow{3}{*}{2} & \multirow{3}{*}{116.030} & \multirow{3}{*}{13.662} & \multirow{3}{*}{0.000} \\
\hline & $30-49$ & 18.19 & 2.227 & 3 & 20 & & & & & \\
\hline & 50 and more & 16.25 & 5.160 & 3 & 20 & & & & & \\
\hline \multirow{4}{*}{ Education level } & No formal education & 20.00 & & 20 & 20 & \multirow{4}{*}{608.407} & \multirow{4}{*}{3} & & & \\
\hline & Primary level & 6.50 & 4.950 & 3 & 10 & & & & & \\
\hline & Secondary school & 14.41 & 4.323 & 4 & 20 & & & 202.802 & 26.384 & 0.000 \\
\hline & $\begin{array}{l}\text { University/Tertiary } \\
\text { institution }\end{array}$ & 17.68 & 2.589 & 3 & 20 & & & & & \\
\hline & $1-2$ & 17.96 & 2.349 & 9 & 20 & & & & & \\
\hline $\begin{array}{l}\text { Numbers of people } \\
\text { in the household }\end{array}$ & $3-5$ & 17.24 & 3.243 & 3 & 20 & 76.133 & 2 & 38.067 & 4.309 & 0.014 \\
\hline & 6 or more & 16.81 & 3.044 & 8 & 20 & & & & & \\
\hline & $\begin{array}{c}\text { Above average }(301-500 \\
\text { USD) }\end{array}$ & 17.98 & 2.361 & 9 & 20 & & & & & \\
\hline Monthly income & Affluent (> 500 USD) & 18.87 & 1.604 & 11 & 20 & 545.740 & 3 & 181.913 & 23.251 & 0.000 \\
\hline & Average (100-300 USD) & 16.54 & 3.672 & 3 & 20 & & & & & \\
\hline & Poor (< 100 USD) & 16.15 & 2.837 & 4 & 20 & & & & & \\
\hline & Total & 17.37 & 2.994 & 3 & 20 & & & & & \\
\hline
\end{tabular}

Table 2. Level of nutrition related apps/software usage and reasons behind ( $N=460)$

\begin{tabular}{|c|c|}
\hline Questions & Answers distribution \\
\hline 1. Do you know what a "balanced diet" is? & Yes $(93.9 \%)$; No $(6.1 \%)$ \\
\hline 2. Where did you hear about? & $\begin{array}{l}\text { I have never heard about }(5.7 \%) \text {; Doctor, nutritionist or dietician }(32.4 \%) \text {; Friends or relatives }(22.2 \%) \text {; } \\
\text { Nutrition courses }(50.4 \%) \text {; Personal reading }(32.2 \%) \text {; Radio or TV }(27 \%) \text {; Social media }(28.3 \%)\end{array}$ \\
\hline $\begin{array}{l}\text { 3. Do you think you apply the principles of } \\
\text { "balanced diet" in your day-to-day life? }\end{array}$ & I do not know (10.7\%); No (41.5\%); Yes $(47.8 \%)$ \\
\hline $\begin{array}{l}\text { 4. Which Nutrition/Fitness apps or software } \\
\text { do you use? }\end{array}$ & $\begin{array}{l}\text { I do not use one (82\%); Apple health }(0.9 \%) \text {; CarbsControl }(1.1 \%) \text {; Fat burning }(0.2 \%) \text {; FatSecret }(0.4 \%) \text {; } \\
\text { Fitbit }(2.8 \%) \text {; Fitocracy }(1.1 \%) \text {; Fiton }(0.2 \%) \text {; Fooducate }(1.1 \%) \text {; Google Fit }(0.2 \%) \text {; Huawei Health App } \\
(0.4 \%) \text {; Mi Fit }(0.2 \%) \text {; MyFitnessPal }(3.7 \%) \text {; MyPlate }(2.2 \%) \text {; MyNetDiary }(0.4 \%) \text {; Nutri Survey }(0.2 \%) \text {; } \\
\text { Samsung Health app (7.4\%); Strava health app }(0.2 \%)\end{array}$ \\
\hline $\begin{array}{l}\text { 5. How would you rate their effectiveness in } \\
\text { solving the problem you are using them for } \\
\text { (expectations)? }\end{array}$ & I do not use one (82\%); Average (7.6\%); Excellent (1.7\%); Good (7.8\%); Poor $(0.9 \%)$ \\
\hline $\begin{array}{l}\text { 6. Since when have you started using } \\
\text { Nutrition apps or software? }\end{array}$ & $\begin{array}{l}\text { I do not use one }(82 \%) ; 1-5 \text { years }(10.7 \%) ; 6-10 \text { Years }(1.1 \%) \text {; Above } 10 \text { years }(0.9 \%) \text {; Less than one } \\
\text { year }(4.8 \%) \text {; Since COVID-19 in the country }(0.7 \%)\end{array}$ \\
\hline $\begin{array}{l}\text { 7. Do you refer more often to it during this } \\
\text { lockdown period associated to the COVID- } \\
19 \text { pandemic? }\end{array}$ & I do not use one (82\%); No (11.1); Yes (7\%) \\
\hline
\end{tabular}


Table 3. Variation of the Nutri apps/software usage level with the sociodemographic variables of the population and their healthy status $(\mathrm{N}=\mathbf{4 6 0})$

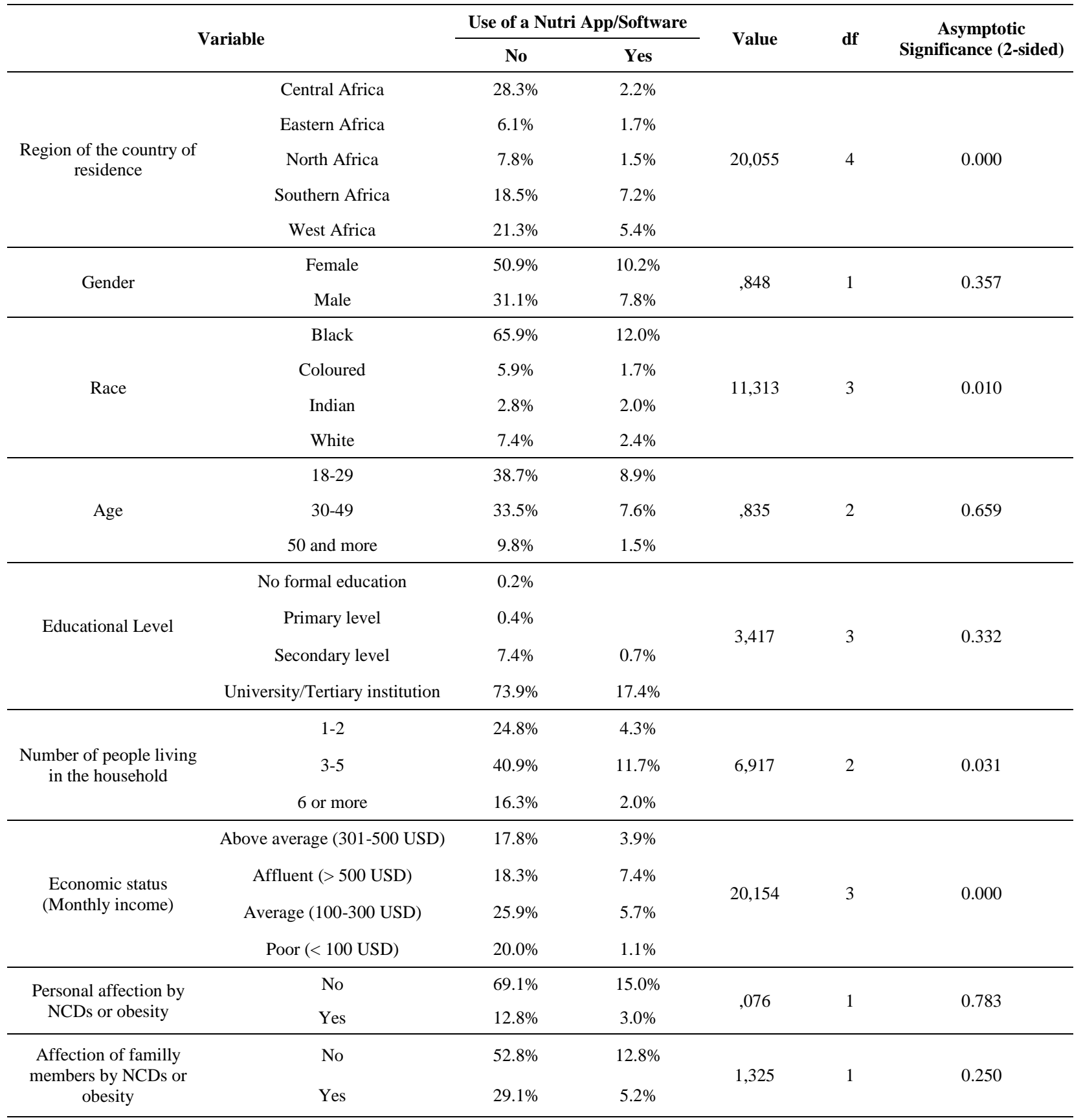

\subsection{Population Opinion Regarding Nutri-apps/software}

Table 4 gives an overview of the surveyed population's opinion about different statements made concerning nutrition app/software. Whatever the statement, the percentage of the population who declared not having any idea about ("I do not know") was always lower than the non-users percentage (82\%). For this non-users sub-population, if not neutral, they tended to think nutrition apps and software are not complex to use, not adapted to foods available in their context, not boring to use, mainly made for weight change, effective for diet monitoring, useful to improve eating habits but will prefer to have advice from a nutritionist or dietician. Similar opinion was reported by the users except that they correctly do not think that app/software are mainly made for weight change. A high interest in learning more about Nutrition app/software was noticed among the population (64.8\%) with $25.9 \%$ being neutral. Changing individual health behaviours is challenging but convenience, cost, culture, social acceptance, comfort, marketing, product placement, store placement, advertisements, brand trust, ingredients, allergies, kitchen access, serving size, and so much more influence behaviours surrounding food choice [25]. Eating healthy has become a challenge that many simply cannot attain. Health focused smartphone apps have the ability to break through barriers and enable users to make healthier choices [26]. Creating healthy behaviour changes requires making the healthy choice in regard to food consumption. 
Table 4. Users and non-users opinion concerning Nutri Apps and software (N=460)

\begin{tabular}{|c|c|c|c|c|c|c|c|}
\hline \multirow{2}{*}{ Statement } & \multirow{2}{*}{$\begin{array}{l}\text { Users of a Nutri } \\
\text { app/software }\end{array}$} & \multicolumn{6}{|c|}{ Opinion } \\
\hline & & $\begin{array}{l}\text { I do not } \\
\text { know }\end{array}$ & Agree & $\begin{array}{l}\text { Strongly } \\
\text { Agree }\end{array}$ & Neutral & Disagree & $\begin{array}{l}\text { Strongly } \\
\text { disagree }\end{array}$ \\
\hline \multirow{2}{*}{$\begin{array}{l}\text { 1. Nutrition apps and software are } \\
\text { complex to use }\end{array}$} & No & $58.5 \%$ & $3.7 \%$ & $0.9 \%$ & $8.3 \%$ & $8.3 \%$ & $2.4 \%$ \\
\hline & Yes & $0.7 \%$ & $3.0 \%$ & $0.2 \%$ & $4.8 \%$ & $7.4 \%$ & $2.0 \%$ \\
\hline \multirow{2}{*}{$\begin{array}{l}\text { 2. They are not adapted to foods } \\
\text { available in my context }\end{array}$} & No & $56.5 \%$ & $8.0 \%$ & $4.8 \%$ & $6.5 \%$ & $4.6 \%$ & $1.5 \%$ \\
\hline & Yes & $1.1 \%$ & $6.3 \%$ & $0.9 \%$ & $4.3 \%$ & $4.6 \%$ & $0.9 \%$ \\
\hline \multirow{2}{*}{ 3. They are boring to use } & No & $56.3 \%$ & $4.3 \%$ & $0.7 \%$ & $8.5 \%$ & $9.1 \%$ & $3.0 \%$ \\
\hline & Yes & $0.7 \%$ & $2.6 \%$ & $0.2 \%$ & $3.9 \%$ & $8.3 \%$ & $2.4 \%$ \\
\hline \multirow{2}{*}{$\begin{array}{l}\text { 4. They are mainly made for weight } \\
\text { change }\end{array}$} & No & $48.9 \%$ & $13.0 \%$ & $1.7 \%$ & $9.6 \%$ & $6.5 \%$ & $2.2 \%$ \\
\hline & Yes & $0.7 \%$ & $5.4 \%$ & $1.1 \%$ & $2.6 \%$ & $6.7 \%$ & $1.5 \%$ \\
\hline \multirow{2}{*}{$\begin{array}{l}\text { 5. Diet monitoring using these tools are } \\
\text { effective }\end{array}$} & No & $56.7 \%$ & $11.7 \%$ & $2.0 \%$ & $9.8 \%$ & $1.3 \%$ & $0.4 \%$ \\
\hline & Yes & $1.1 \%$ & $7.6 \%$ & $2.2 \%$ & $4.8 \%$ & $1.7 \%$ & $0.7 \%$ \\
\hline \multirow{2}{*}{$\begin{array}{l}\text { 6. They are useful tools to improve } \\
\text { behaviour related to nutrition }\end{array}$} & No & $47.0 \%$ & $20.4 \%$ & $4.6 \%$ & $8.5 \%$ & $1.1 \%$ & $0.4 \%$ \\
\hline & Yes & $0.4 \%$ & $10.4 \%$ & $1.7 \%$ & $4.3 \%$ & $1.1 \%$ & - \\
\hline \multirow{2}{*}{$\begin{array}{l}\text { 7. I will prefer to have advice from a } \\
\text { nutritionist or dietician rather than using } \\
\text { those tools }\end{array}$} & No & $0.4 \%$ & $26.5 \%$ & $15.0 \%$ & $30.7 \%$ & $5.0 \%$ & $4.3 \%$ \\
\hline & Yes & $0.2 \%$ & $7.2 \%$ & $2.6 \%$ & $5.9 \%$ & $1.7 \%$ & $0.4 \%$ \\
\hline \multirow{2}{*}{$\begin{array}{l}\text { 8. I am interested in learning more about } \\
\text { Nutrition software or apps }\end{array}$} & No & - & $33.3 \%$ & $17.6 \%$ & $22.20 \%$ & $4.1 \%$ & $4.8 \%$ \\
\hline & Yes & $0.2 \%$ & $10.0 \%$ & $3.9 \%$ & $3.7 \%$ & $0.2 \%$ & - \\
\hline
\end{tabular}

\subsection{Prevalence of Non-Communicable Diseases and Obesity within the Population}

Up to $84.13 \%$ of the surveyed population declared to be neither concerned by obesity nor by an NCDs, but only $65.65 \%$ declared their family members too (Figure 1). Cardiovascular diseases, diabetes, Chronic respiratory diseases and cancer were the most represented diseases among the sick sub-populations and respondents' families. Obesity was also reported by few respondents $(7.39 \%$ ) and to be present in $6.74 \%$ of families. No significant correlation was noticed between the health status of the respondents or its family members and the use of nutrition apps/software. COVID-19 has yet been described as more lethal for those suffering from NCDs [1;10]. Adoption of healthy lifestyles through the use of nutrition-related apps/software might therefore be helpful for those subpopulations.

\begin{tabular}{|c|c|c|c|c|c|}
\hline Osteoporosis & 0.65 & (a) & Osteoporosis & 2.39 & (b) \\
\hline Obesity & 7.39 & & Obesity & 6.74 & \\
\hline Mental illness & 0.22 & & Mental illness & 0.87 & \\
\hline Liver disease & 1.52 & & Liver disease & 0.87 & \\
\hline Fibromyalgia & 0.65 & & Fibromyalgia & 0.43 & \\
\hline Chronic kidney disease & 0.65 & & Chronic kidney disease & 1.09 & \\
\hline Chronic respiratory diseases & |1 2.83 & & Chronic respiratory diseases & IIII 4.78 & \\
\hline Cardiovascular diseases & IIII 5.22 & & Cardiovascular diseases & 16.09 & \\
\hline Cancer & 2.17 & & Cancer & 1.52 & \\
\hline Cataract & 1.30 & & Cataract & 3.26 & \\
\hline Diabetes & |1 2.83 & & Diabetes & |யш|| 12.17 & \\
\hline \multirow[t]{3}{*}{ None } & 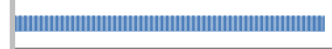 & 84.13 & None & 65.65 & \\
\hline & $\begin{array}{lllll}0 & 20 & 40 & 60 & 80\end{array}$ & 100 & & $\begin{array}{llll}20 & 40 & 60 & 80\end{array}$ & 100 \\
\hline & \multicolumn{2}{|l|}{ Percentage $(\%)$} & \multicolumn{3}{|c|}{ Percentage (\%) } \\
\hline
\end{tabular}

Figure 1. Prevalence of NCDs and Obesity within the surveyed population (a) and their families (b) 


\section{Conclusion}

This study demonstrated that the use of nutrition Apps/software in Africa is still very low, but people are interested in learning more about. Measures promoting their use in this COVID-19 pandemic time may therefore be of interest in order to limit the associated double burden malnutrition and avoid a resurgence of non-communicable diseases across the continent as the Computer, Smartphone and internet use experience is rising continuously. Furthermore, development of apps/software which incorporate healthy African indigenous foods available is imperative as this will go a long way to encourage the use of these tools and increase their effectiveness in Africa.

\subsection{Limitations of the Study}

This study is limited to an online survey by the COVID-19 lockdowns which did not allow the researchers move to certain rural/semi-urban settings to include participants from those areas. Hence, this study only covers a particular socio-economic class of people who are educated and almost 80\% earning 100USD or above per month. This work which takes its strength from its international dimension is also limited by its relatively small sample size but already gave an overview of parameters determining nutrition apps usage in Africa.

\section{Declarations}

\subsection{Author Contributions}

Conceptualization, A.T., H.K., G.K., and E.O.O.; formal analysis, A.T., H.K., G.K., and E.O.O.; writing一original draft preparation, A.T., H.K., G.K., and E.O.O.; writing-review and editing, A.T., H.K., G.K., and E.O.O. All authors have read and agreed to the published version of the manuscript.

\subsection{Funding}

The authors received no financial support for the research, authorship, and/or publication of this article.

\subsection{Acknowledgements}

The authors wish to thank all the people who took part to the survey.

\subsection{Ethical Approval}

The research proposal was reviewed and approved by the Ethics Committee of Research of the University of Johannesburg. All participating respondents voluntarily and anonymously filled the online survey form.

\subsection{Data Availability Statement}

The data presented in this study are available on request from the corresponding author.

\subsection{Conflict of Interest}

The authors declare that they have no known competing financial interests or personal relationships that could have appeared to influence the work reported in this paper.

\section{References}

[1] Hamer, M., Kivimäki, M., Gale, C. R., \& Batty, G. D. (2020). Lifestyle risk factors, inflammatory mechanisms, and COVID-19 hospitalization: A community-based cohort study of 387,109 adults in UK. Brain, Behavior, and Immunity, 87, $184-187$. doi:10.1016/j.bbi.2020.05.059.

[2] López-Bueno, R., Calatayud, J., Casaña, J., Casajús, J.A., Smith, L., Tully, M.A., Andersen, L.L., \& López-Sánchez, G.F. (2020). COVID-19 Confinement and Health Risk Behaviors in Spain. Frontiers in Psychology, 11:1426. doi:10.3389/fpsyg.2020.01426

[3] Stanton, R., To, Q.G., Khalesi, S., Williams, S.L., Alley, S.J., Thwaite, T.L., Fenning, A.S., \& Vandelanotte, C. (2020). Depression, anxiety and stress during COVID-19: Associations with changes in physical activity, sleep, tobacco and alcohol use in Australian adults. International Journal of Environmental Research and Public Health, 17(11). doi:10.3390/ijerph17114065

[4] Bracale, R., \& Vaccaro, C.M. (2020). Changes in food choice following restrictive measures due to Covid-19. Nutrition, Metabolism and Cardiovascular Diseases. doi:10.1016/j.numecd.2020.05.027

[5] Chaudhry, R., Dranitsaris, G., Mubashir, T., Bartoszko, J., \& Riazi, S. (2020). A country level analysis measuring the impact of government actions, country preparedness and socioeconomic factors on COVID-19 mortality and related health outcomes. EClinicalMedicine. doi:10.1016/j.eclinm.2020.100464

[6] Di Renzo, L., Gualtieri, P., Pivari, F., Soldati, L., Attinà, A., Cinelli, G., Cinelli, G., Leggeri, C., Caparello, G., Barrea, L., Scerbo, F., Esposito, E., \& De Lorenzo, A. (2020). Eating habits and lifestyle changes during COVID-19 lockdown: An Italian survey. Journal of Translational Medicine, 18, 229. doi:10.1186/s12967-020-02399-5 
[7] World Health Organization. (2018a). Noncommunicable Diseases Country Profiles 2018. World Health Organization. Available online: https://apps.who.int/iris/bitstream/handle/10665/274512/9789241514620-eng.pdf (accessed on January 2021).

[8] World Health Organization. (2018b). Noncommunicable diseases. Available online: https://www.who.int/news-room/factsheets/detail/noncommunicable-diseases (accessed on January 2021).

[9] World Health Organization. (2020a). Coronavirus disease 2019 (COVID-19) Situation Report-82. Available online: https://www.who.int/docs/default-source/coronaviruse/situation-reports/20200411-sitrep-82-covid-19.pdf?sfvrsn=74a5d15_2 (accessed on February 2021).

[10] Spires, M., Delobelle, P., Sanders, D., Puoane, T., Hoelzel, P., \& Swart, R. (2016). Diet-related non-communicable diseases in South Africa: determinants and policy responses. South African Health Review, 2016(1), 35-42.

[11] World Health Organization. (2020b). COVID-19 and NCDs. Available online: https://www.who.int/docs/defaultsource/inaugural-who-partners-forum/covid-19-and-ncds---final---corr7.pdf (accessed on January 2021).

[12] Palmer, K., Monaco, A., Kivipelto, M., Onder, G., Maggi, S., Michel, J.P., Prieto, R., Sykara, G., \& Donde, S. (2020). The potential long-term impact of the COVID-19 outbreak on patients with non-communicable diseases in Europe: consequences for healthy ageing. Aging clinical and experimental research, 32, 1189-1194. doi:10.1007/s40520-020-01601-4

[13] DiFilippo, K.N., Huang, W.H., Andrade, J.E., \& Chapman-Novakofski, K.M. (2015). The use of mobile apps to improve nutrition outcomes: A systematic literature review. J. Telemed. Telecare. doi:10.1177/1357633X15572203

[14] Gilliland, J., Sadler, R., Clark, A., O’Connor, C., Milczarek, M., \& Doherty, S. (2015). Using a smartphone application to promote healthy dietary behaviours and local food consumption. BioMed Research International. Int. doi:10.1155/2015/841368

[15] Karduck, J., \& Chapman-Novakofski, K. (2018). Results of the Clinician Apps Survey, How Clinicians Working With Patients With Diabetes and Obesity Use Mobile Health Apps. Journal of Nutrition Education and Behavior, 50(1), 62-69. doi:10.1016/j.jneb.2017.06.004

[16] Zhao, J., Freeman, B., \& Li, M. (2016). Can mobile phone apps influence people's health behavior change? An evidence review. Journal of Medical Internet Research, 18(11), 287. doi:10.2196/jmir.5692

[17] Onyango, A.W., Jean-Baptiste, J., Samburu, B., \& Mahlangu, T.L.M. (2019). Regional Overview on the Double Burden of Malnutrition and Examples of Program and Policy Responses: African Region. Annals of Nutrition and Metabolism. doi:10.1159/000503671

[18] Poushter, J., Bishop, C., \& Chwe, H. (2018). Social media use continues to rise in developing countries, but plateaus across developed ones. Washington: Pew Internet and American Life Project. Available online: http://www.pewglobal.org/wpcontent/uploads/sites/2/2018/06/Pew-Research-Center_Global-Tech-Social-Media-Use_2018.06.19.pdf (accessed on August 2020).

[19] Ahmed, R., Robinson, R., Elsony, A., Thomson, R., Bertel Squire, S., Malmborg, R., Burney, P., \& Mortimer, K. (2018). A comparison of smartphone and paper data-collection tools in the Burden of Obstructive Lung Disease (BOLD) study in Gezira state, Sudan. PLoS One, 13(3): e0193917. doi:10.1371/journal.pone.0193917

[20] West, J.H., Belvedere, L.M., Andreasen, R., Frandsen, C., Hall, P.C., \& Crookston, B.T., (2017). Controlling Your “App”etite: How Diet and Nutrition-Related Mobile Apps Lead to Behavior Change. JMIR mHealth uHealth. 5(7), e95. doi:10.2196/mhealth.7410

[21] Mateo, G.F., Granado-Font, E., Ferré-Grau, C., \& Montaña-Carreras, X. (2015). Mobile phone apps to promote weight loss and increase physical activity: A systematic review and meta-analysis. Journal of medical Internet research. JMIR Publications Inc, 17(11), p. e253. doi:10.2196/jmir.4836

[22] Kunst, A. (2019). Percentage of U.S. adults who would use an app to track their diet and nutrition as of 2017, by age. Available online: https://www.statista.com/statistics/698919/us-adults-that-would-use-an-app-to-track-their-diet-by-age/ (accessed on January 2021).

[23] Bucuta, A. (2015). A Review of the Specific Characteristics of the Generation Y Consumer. Marketing From Information to Decision, (8), 38-47.

[24] Rosenbloom, C. (2017) 9 ways millennials are changing the way we eat - The Washington Post, The Washington Post. Available online: https://www.washingtonpost.com/lifestyle/wellness/9-ways-millennials-are-changing-the-way-we-eat/2018/ 02/20/ 6bb2fe60-11eb-11e8-8ea1-c1d91fcec3fe_story.html (accessed on August 2020).

[25] Payne, H.E., Lister, C., West, J.H., \& Bernhardt, J.M. (2015). Behavioral Functionality of Mobile Apps in Health Interventions: A Systematic Review of the Literature. JMIR mHealth uHealth, 3(1), 20. doi:10.2196/mhealth.3335

[26] Ipjian, M.L., \& Johnston, C.S. (2017). Smartphone technology facilitates dietary change in healthy adults. Nutrition, 343-347. doi:10.1016/j.nut.2016.08.003. 